\title{
Determination of Optimum Insulation Thickness for Different Insulation Applications Considering Condensation
}

\author{
Omer KAYNAKLI, Ali Husnu BADEMLIOGLU, Hande Tufekci UFAT
}

\begin{abstract}
In this study, thermal insulation thickness used in the outer walls of buildings composing of different insulation applications having the same thermal resistance was optimized by considering condensation. The minimum insulation thickness required to prevent condensation (i.e. optimum insulation thickness) in building structural component was determined. Heat and mass transfer calculations within the structural component were performed with respect to various indoor-outdoor temperature and relative humidity values and results were given in graphs. It was observed that optimum insulation thickness is generally increased with an increase in the indoor temperature, indoor relative humidity and outdoor relative humidity. It was concluded that type of insulation application does not significantly affect optimum insulation thickness at low and medium level $\left(\theta_{i}<0.60\right)$ indoor relative humidity conditions. It was also observed that externally insulated wall application generally yields better results at high indoor and outdoor relative humidity conditions.
\end{abstract}

Keywords: building outer wall; condensation; optimization; thermal insulation

\section{INTRODUCTION}

Condensation begins when the partial pressure of water vapour diffusing into building material is equal to the saturation pressure of water vapour at any point within inner layers. This is called condensation or sweating. It results in undesirable outcomes such as damage to the materials, reduced strength and increased heat losses due to increased overall heat transfer coefficient. Condensation, which is most often seen on the surface of building materials, may also sometimes stay in the building materials. There is no problem with respect to structural component in this if water vapour goes outside to the environment in gas phase. However, water vapour may turn into liquid phase during passing through the structural component. In this case, condensed water may cause mildew, fungal growth, odors, and deterioration of dye and building materials or adversely affected thermal insulation on the walls.

Resistance of structural component to the movement of water vapour should be increased in order to prevent condensation. The most simple and basic way for this is increasing the thickness of insulation. Questions arise at this point regarding the extent of increment in insulation thickness and variation of such an increment according to environmental conditions.

There are a number of studies in the literature on the optimization of the insulation thickness to be applied on the outer walls [1-8]. The degree-day method was used in those studies for the heat loss calculations. Minimization of the total insulation costs and the energy source used (such as natural gas, coal, electricity) was taken as basis for the optimization of insulation thickness. In some studies [9-13], the solar-air (sol-air) temperature concept was used instead of classical outdoor temperature in order to consider the effect of solar radiation. Al-Sanea et al. [14] has also taken into account the effect of the wind by using the equation of heat transfer coefficient for building in his study in which he studied air gap in building materials, and insulation configuration. However, calculation of optimum insulation thickness is mainly based on energy cost minimization in all these studies and condensation in building materials is not taken into consideration.

Quite a few studies in literature consider condensation for calculation of optimum insulation thickness. Atmaca and Kargici [15] investigated vapour transfer and condensation phenomenon in a building (which is insulated internally and externally) in the province of Konya. They applied the insulation material (3 cm thick glass wool) both internally and externally, respectively, and determined that condensation continues when insulated internally and, on the other hand, condensation ceases in externally insulated case. Heperkan et al. [16] developed a computer program facilitating vapor diffusion and condensation calculations and detecting the point where condensation occurs in building material. Arslan and Kose [17] investigated thermoeconomic optimization of the insulation thickness by considering condensation for the province of Kutahya. Ucar [18] calculated optimum insulation thickness by using exergy analysis at various indoor temperatures (18, 20 and $22{ }^{\circ} \mathrm{C}$ ) for four provinces located in different climate zones (Antalya, Istanbul, Elazig and Erzurum). She found with this study that energy savings of $49.5 \%$, $60.5 \%, 66.8 \%$ and $79 \%$ are provided for an indoor temperature of $20{ }^{\circ} \mathrm{C}$ in Antalya, Istanbul, Elazig and Erzurum when optimum insulation was applied. In exergoeconomic analysis, amount of water condensed in the building material was taken into account; however, effect of indoor and outdoor relative humidity on condensation and insulation thickness was not investigated.

In this study, thermal insulation thickness used in the outer walls of buildings composing of different insulation applications having the same thermal resistance was optimized by considering condensation. The minimum (optimum) insulation thickness required to prevent condensation in the outer wall of the building was evaluated for three different applications (internal, external and sandwich insulation). Effect of various indoor and outdoor environmental conditions (temperature and relative humidity) on the optimal insulation thickness was investigated and, it was 
examined in which conditions the type of application gives better results.

\section{MATERIAL AND METHOD \\ 2.1 Heat Transfer and Water Vapour Diffusion in Composite Plane Walls}

Types of outer walls composing of different insulation applications having the same thermal resistance are given in Fig. 1.

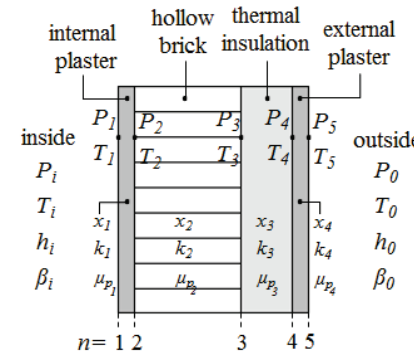

(a) Externally Insulated Wall

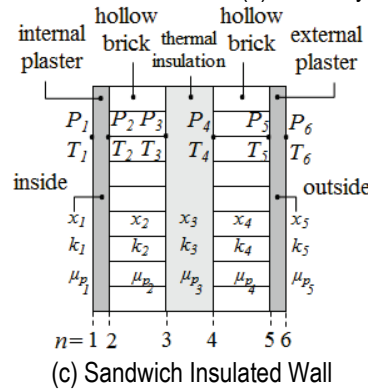

(c) Sandwich Insulated Wall

Figure 1 Wall types composing of different insulation applications

In these applications, indoor convective heat transfer coefficient $h_{i}$, outdoor convective heat transfer coefficient $h_{0}$, thermal conductivity of the materials $k$ and their thickness $x$ are given so that steady-state heat flux can be written as:

$$
\begin{aligned}
& q=h_{i}\left(T_{i}-T_{1}\right) \Rightarrow T_{1}=T_{i}-\frac{q}{h_{i}}, \\
& q=\frac{k_{n}}{x_{n}}\left(T_{n}-T_{n+1}\right) \Rightarrow T_{n+1}=T_{n}-\frac{q}{\frac{k_{n}}{x_{n}}} .
\end{aligned}
$$

Eq. (2) is used for the calculations in building material layers while Eq. (1) for indoor and outdoor calculations. In a similar manner, heat flux is given as follows for the entire composite plane wall:

$$
q=\frac{T_{i}-T_{o}}{\frac{1}{h_{i}}+\sum \frac{x_{n}}{k_{n}}+\frac{1}{h_{d}}}=\frac{T_{i}-T_{o}}{R_{w}+\frac{x_{i n s}}{k_{i n s}}} .
$$

Similar to the Fourier's law of heat conduction, onedimensional steady-state water vapour diffusion differential equation is defined as follows:

$w=-\mu_{p} \frac{\mathrm{d} P}{\mathrm{~d} x}$, where $w$, water vapour passing through unit surface area

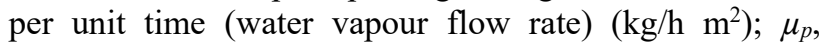
vapour permeability of the building material $(\mathrm{kg} / \mathrm{h} \mathrm{m}$ $\mathrm{kPa}) ; \mathrm{d} P / \mathrm{d} x$, partial pressure of water vapour gradient $(\mathrm{kPa} / \mathrm{m})$. The direction of heat flow is to the lower temperature from the higher temperature with respect to the Fourier's law of heat conduction and, the direction of water vapour flow is to the lower partial pressure of water vapour from the higher partial pressure in relation with the Fick's law.

Similar to the heat transfer, indoor vapour permeability coefficient $\beta_{i}$, outdoor vapour permeability coefficient $\beta_{o}$, vapour permeability of the building materials $\mu_{p}$ and their thickness $x$ are given so that steady-state water vapour flow rate in the wall can be written as:

$$
\begin{aligned}
& w=\beta_{i}\left(P_{i}-P_{1}\right) \Rightarrow P_{1}=P_{i}-\frac{w}{\beta_{i}}, \\
& w=\frac{\mu_{p_{n}}}{x_{n}}\left(P_{n}-P_{n+1}\right) \Rightarrow P_{n+1}=P_{n}-\frac{w}{\frac{\mu_{p_{n}}}{x_{n}}} .
\end{aligned}
$$

Eq. (6) is used for the calculations in building material layers while Eq. (5) for indoor and outdoor calculations. Water vapour flow rate is given as follows for the entire composite plane wall:

$$
w=\frac{P_{i}-P_{o}}{\frac{1}{\beta_{i}}+\sum \frac{x_{n}}{\mu_{p_{n}}}+\frac{1}{\beta_{o}}} .
$$

In Eq. (7), indoor partial pressure of water vapour $P_{i}$, outdoor partial pressure of water vapour $P_{o}$ and their relationship between the indoor and outdoor relative humidity data is as follows:

$$
\theta_{i}=\frac{P_{i}}{P_{s, i}} ; \theta_{o}=\frac{P_{o}}{P_{s, o}}
$$

In Eq. (8), $P_{s, i}$ and $P_{s, o}$ the saturation water vapour pressures are at indoor and outdoor temperatures, respectively. Vapour permeability resistance $(\delta)$ is used instead of the vapour permeability of the building materials $\left(\mu_{p}\right)$ given in Eq. (7) and vapour permeability resistance is defined as follows:

$\delta=\frac{1}{\mu_{p}}$

Vapour permeability resistance is given in terms of the vapour diffusion resistance factor of material $(\mu)$ and vapour permeability resistance of air $\left(\delta_{\text {air }}\right)$ as follows:

$\delta=\mu \delta_{\text {air }}$,

$\delta_{\text {air }}$ is generally taken as $1.5 \times 10^{3} \mathrm{kPa} \mathrm{m} \mathrm{h} / \mathrm{kg}[15,17]$. In addition, it is specified that this value can be used in water vapour diffusion processes within the range of $-20{ }^{\circ} \mathrm{C}$ to 
$+30{ }^{\circ} \mathrm{C}$. The vapor permeability resistance of air can be calculated with Eq. (11) for different applications [19]:

$$
\delta_{\text {air }}=\frac{D}{R T}
$$

where $R$ the gas constant for water vapor $(\mathrm{Nm} / \mathrm{mg} \mathrm{K}), T$ temperature $(\mathrm{K})$ and $D$ water vapor diffusion coefficient $\left(\mathrm{m}^{2} / \mathrm{h}\right)$. As a result, Eq. (7) becomes:

$$
w=\frac{P_{i}-P_{o}}{\frac{1}{\beta_{i}}+\left(1.5 \times 10^{3}\right) \sum x_{n} \mu_{n}+\frac{1}{\beta_{o}}} .
$$

Indoor vapour permeability coefficient can be taken as $\beta_{i}=0.111 \mathrm{~kg} / \mathrm{m}^{2} \mathrm{~h} \mathrm{kPa}$ and outdoor vapour permeability coefficient as $\beta_{o}=0.39 \mathrm{~kg} / \mathrm{m}^{2} \mathrm{~h} \mathrm{kPa}$ [20].

\subsection{Distribution of Temperature and Partial Pressure in the Wall}

Possible temperature and pressure distribution in the building are shown schematically in Fig. 2 for different types of walls. Possible condensation point (4 plane lines for internal and external insulation, 5 plane lines for sandwich insulation) where partial and saturation pressures intersect (under typical indoor and outdoor environmental conditions) can be seen in the figure. $P_{S}$ pressure at each point shown in the figure is the saturation pressure of water vapour at that temperature. The temperature distribution within the plane wall is calculated with Eq. (1)-(3) while partial pressures with Eq. (5) and (12) for each point.

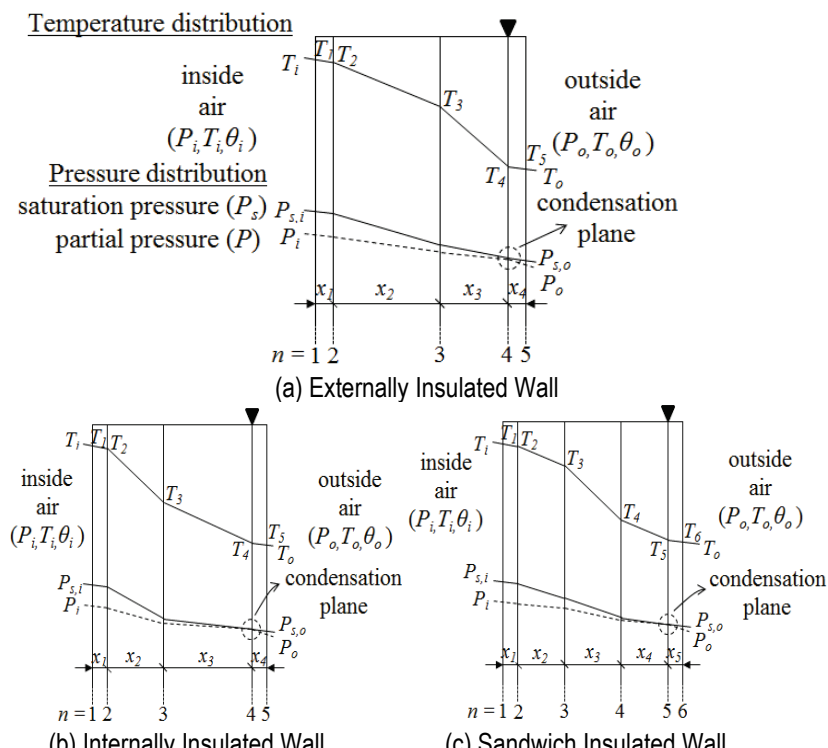

Figure 2 Possible temperature and pressure distribution in different wall types

\section{RESULTS OF THE STUDY AND DISCUSSION}

The constants and variables used in this study are given in Tab. 1.

Heat and mass transfer through the unit area of the wall was calculated for three different insulation applications and then, temperature and partial pressure distributions were obtained in the wall by the analysis performed by using the data in Tab. 1 . The temperature distribution in the wall is given in Tab. $2 a$ and $2 b$ for various insulation applications. Saturation and partial pressure values in the wall are given for external, internal and sandwich applications in Tab. $3 a, 3 b$ and $3 c$, respectively. Indoor and outdoor conditions are taken respectively as $21{ }^{\circ} \mathrm{C}, 0.55$ and $-3{ }^{\circ} \mathrm{C}, 0.75$ in these analyses.

It can be seen from Tab. $2 \mathrm{a}$ and $2 \mathrm{~b}$ that overall heat transfer coefficient and heat flux through the wall decrease although an increase in insulation thickness is expected. When the temperature distribution within the wall structure is examined, it is observed that temperatures up to the insulating material $\left(T_{1}, T_{2}\right.$ and $T_{3}$ for externally insulated wall; $T_{1}$ and $T_{2}$ for internally insulated wall; $T_{1}, T_{2}$ and $T_{3}$ for sandwich insulated wall) increase with increasing thickness of the insulation for all

\begin{tabular}{|c|c|c|c|}
\hline \multicolumn{3}{|c|}{ Parameter } & Value \\
\hline \multicolumn{4}{|l|}{ Indoor Conditions } \\
\hline \multicolumn{3}{|l|}{ Temperature, ${ }^{\circ} \mathrm{C}$} & 18 to 32 \\
\hline \multicolumn{3}{|l|}{ Relative humidity } & 0.30 to 0.90 \\
\hline \multicolumn{3}{|c|}{ Convective heat transfer coefficient, $\mathrm{W} / \mathrm{m}^{2} \mathrm{~K}$} & $8.3[21]$ \\
\hline \multicolumn{3}{|c|}{ Vapour permeability coefficient, $\mathrm{kg} / \mathrm{m}^{2} \mathrm{~h} \mathrm{kPa}$} & $0.111[20]$ \\
\hline \multicolumn{4}{|l|}{ Outdoor Conditions } \\
\hline \multicolumn{3}{|l|}{ Temperature, ${ }^{\circ} \mathrm{C}$} & -14 to 4 \\
\hline \multicolumn{3}{|l|}{ Relative humidity } & 0.30 to 0.95 \\
\hline \multicolumn{3}{|c|}{ Convective heat transfer coefficient, $\mathrm{W} / \mathrm{m}^{2} \mathrm{~K}$} & $34[21]$ \\
\hline \multicolumn{3}{|c|}{ Vapour permeability coefficient, $\mathrm{kg} / \mathrm{m}^{2} \mathrm{~h} \mathrm{kPa}$} & $0.39[20]$ \\
\hline Type of Wall* & Thickness & $k(\mathrm{~W} / \mathrm{mK})$ & ) $\quad \mu(-)$ \\
\hline Externally Insulated Wall & $x(\mathrm{~m})$ & {$[8,21,22]$} & {$[15,17]$} \\
\hline Internal plastering & 0.02 & 0.87 & 10 \\
\hline Brick & 0.2 & 0.45 & 6.8 \\
\hline Thermal Insulation & $x$ & 0.034 & 100 \\
\hline External plastering & 0.03 & 1.4 & 16.5 \\
\hline \multicolumn{4}{|l|}{ Internally Insulated Wall } \\
\hline Internal plastering & 0.02 & 0.87 & 10 \\
\hline Thermal Insulation & $x$ & 0.034 & 100 \\
\hline Brick & 0.2 & 0.45 & 6.8 \\
\hline External plastering & 0.03 & 1.4 & 16.5 \\
\hline \multicolumn{4}{|l|}{ Sandwich Insulated Wall } \\
\hline Internal plastering & 0.02 & 0.87 & 10 \\
\hline Brick & 0.1 & 0.45 & 6.8 \\
\hline Thermal Insulation & $x$ & 0.034 & 100 \\
\hline Brick & 0.1 & 0.45 & 6.8 \\
\hline External plastering & 0.03 & 1.4 & 16.5 \\
\hline
\end{tabular}
three applications.

Saturation pressures of water vapour, which is a function of these temperatures, also increase with increasing thickness of the insulation (Tab. 3a, 3b and 3c). Water vapor passing through the wall per unit time decreases with increasing thickness of the insulation. Condensation occurs inside the wall when the partial pressure of water vapor exceeds the saturation pressure. When the pressure values given in Tab. $3 a, 3 b$ and $3 c$ are analyzed, it is observed that condensation occurs (since $P_{s . n}<P_{n}$ ) in the uninsulated wall at the points 3 and 4 (Tab. 3a) for the exterior insulation, at the point 4 for the internal insulation (Tab. 3b) and at the point 5 for the sandwich insulation (Tab. 3c). It is seen in Tab. 3a that condensation can be prevented at the point 3 at first (at $x_{i n s}=0.006 \mathrm{~m}$ ) and then at the point 4 (at $x_{i n s}=0.008 \mathrm{~m}$ ). In a similar way, as can be seen from Tab. $3 b$ and $3 c$, 
increasing insulation thickness eliminates the risk of condensation (at $x_{i n s}=0.008 \mathrm{~m}$ ). As a result, since an insulation thickness of $0.008 \mathrm{~m}$ is the minimum value that can prevent condensation in the concerned indoor and outdoor conditions, this thickness can be considered as the optimal insulation thickness for all three applications.

Table 2a Temperature distribution in the externally and internally insulated wall

\begin{tabular}{|c|c|c|c|c|c|c|c|}
\hline \multirow{2}{*}{$\begin{array}{c}\text { Insulation thickness, } \\
x_{\text {ins }}(\mathrm{m})\end{array}$} & \multirow{2}{*}{$U\left(\mathrm{~W} / \mathrm{m}^{2} \mathrm{~K}\right)$} & \multirow{2}{*}{$Q\left(\mathrm{~W} / \mathrm{m}^{2}\right)$} & \multicolumn{5}{|c|}{ Temperatures * } \\
\hline & & & $T_{1}$ & $T_{2}$ & $T_{3}$ & $T_{4}$ & $T_{5}$ \\
\hline 0 & 1.5655 & 37.57 & $16.47 / 16.47$ & $15.61 / 15.61$ & $-1.09 / 15.61$ & $-1.09 /-1.09$ & $-1.89 /-1.89$ \\
\hline 0.002 & 1.4335 & 34.40 & $16.85 / 16.85$ & $16.06 / 16.06$ & $0.77 / 14.04$ & $-1.25 /-1.25$ & $-1.99 /-1.99$ \\
\hline 0.004 & 1.3220 & 31.73 & $17.18 / 17.18$ & $16.45 / 16.45$ & $2.35 / 12.71$ & $-1.39 /-1.39$ & $-2.07 /-2.07$ \\
\hline 0.006 & 1.2267 & 29.44 & $17.45 / 17.45$ & $16.78 / 16.78$ & $3.69 / 11.58$ & $-1.50 /-1.50$ & $-2.13 /-2.13$ \\
\hline 0.008 & 1.1441 & 27.46 & $17.69 / 17.69$ & $17.06 / 17.06$ & $4.86 / 10.60$ & $-1.60 /-1.60$ & $-2.19 /-2.19$ \\
\hline 0.010 & 1.0720 & 25.73 & $17.90 / 17.90$ & $17.31 / 17.31$ & $5.87 / 9.74$ & $-1.69 /-1.69$ & $-2.24 /-2.24$ \\
\hline 0.012 & 1.0084 & 24.20 & $18.08 / 18.08$ & $17.53 / 17.53$ & $6.77 / 8.99$ & $-1.77 /-1.77$ & $-2.29 /-2.29$ \\
\hline 0.014 & 0.9519 & 22.85 & $18.25 / 18.25$ & $17.72 / 17.72$ & $7.57 / 8.32$ & $-1.84 /-1.84$ & $-2.33 /-2.33$ \\
\hline
\end{tabular}

* The temperature at each point is given for the externally insulated and internally insulated walls, respectively

Table $2 \mathrm{~b}$ Temperature distribution in the sandwich insulated wall

\begin{tabular}{|c|c|c|c|c|c|c|c|c|}
\hline \multirow{2}{*}{$\begin{array}{c}\text { Insulation thickness, } \\
x_{\text {ins }}(\mathrm{m})\end{array}$} & \multirow{2}{*}{$U\left(\mathrm{~W} / \mathrm{m}^{2} \mathrm{~K}\right)$} & \multirow{2}{*}{$q\left(\mathrm{~W} / \mathrm{m}^{2}\right)$} & \multicolumn{6}{|c|}{ Temperatures } \\
\hline & & & $T_{1}$ & $T_{2}$ & $T_{3}$ & $T_{4}$ & $T_{5}$ & $T_{6}$ \\
\hline 0 & 1.5655 & 37.57 & 16.47 & 15.61 & 7.26 & 7.26 & -1.09 & -1.89 \\
\hline 0.002 & 1.4335 & 34.40 & 16.85 & 16.06 & 8.42 & 6.39 & -1.25 & -1.99 \\
\hline 0.004 & 1.3220 & 31.73 & 17.18 & 16.45 & 9.40 & 5.66 & -1.39 & -2.07 \\
\hline 0.006 & 1.2267 & 29.44 & 17.45 & 16.78 & 10.23 & 5.04 & -1.50 & -2.13 \\
\hline 0.008 & 1.1441 & 27.46 & 17.69 & 17.06 & 10.96 & 4.50 & -1.60 & -2.19 \\
\hline 0.010 & 1.0720 & 25.73 & 17.90 & 17.31 & 11.59 & 4.03 & -1.69 & -2.24 \\
\hline 0.012 & 1.0084 & 24.20 & 18.08 & 17.53 & 12.15 & 3.61 & -1.77 & -2.29 \\
\hline 0.014 & 0.9519 & 22.85 & 18.25 & 17.72 & 12.65 & 3.24 & -1.84 & -2.33 \\
\hline
\end{tabular}

Table 3a Partial pressure distribution in the externally insulated wall

\begin{tabular}{|c|c|c|c|c|c|c|c|c|c|c|c|c|c|c|c|c|}
\hline \multirow{2}{*}{$\begin{array}{c}\text { Insulation } \\
\text { thickness, } \\
x_{\text {ins }}(\mathrm{m}) \\
\end{array}$} & \multirow{2}{*}{$\begin{array}{l}\text { Amount of vapour } \\
\text { passing through } \\
\text { wall, } w\left(\mathrm{~g} / \mathrm{m}^{2} \mathrm{~h}\right)\end{array}$} & \multicolumn{15}{|c|}{ saturation pressure $\left(P_{\mathrm{s}}\right)$ / partial pressure $(P)$} \\
\hline & & \multicolumn{3}{|c|}{1} & \multicolumn{3}{|c|}{2} & \multicolumn{3}{|c|}{3} & \multicolumn{3}{|c|}{4} & \multicolumn{3}{|c|}{5} \\
\hline 0 & 0.324 & 1.872 & $/$ & 1.364 & 1.772 & $/ 1$ & 1.267 & 0.563 & $/ 1$ & 0.606 & 0.563 & 1 & 0.606 & 0.530 & $1 /$ & 0.366 \\
\hline 0.002 & 0.295 & 1.918 & $/$ & 1.364 & 1.824 & $/$ & 1.275 & 0.646 & $/$ & 0.674 & 0.556 & 1 & 0.585 & 0.526 & 1 & 0.366 \\
\hline 0.004 & 0.271 & 1.958 & $/$ & 1.364 & 1.869 & 1 & 1.283 & 0.723 & 1 & 0.730 & 0.551 & 1 & 0.567 & 0.523 & 1 & 0.366 \\
\hline 0.006 & 0.251 & 1.992 & $/$ & 1.364 & 1.908 & $/$ & 1.289 & 0.796 & $/$ & 0.778 & 0.546 & 1 & 0.552 & 0.520 & 1 & 0.366 \\
\hline 0.008 & 0.233 & 2.022 & 1 & 1.365 & 1.943 & 1 & 1.295 & 0.864 & 1 & 0.819 & 0.542 & 1 & 0.539 & 0.518 & 1 & 0.366 \\
\hline 0.010 & 0.218 & 2.049 & 1 & 1.365 & 1.974 & 1 & 1.299 & 0.927 & 1 & 0.855 & 0.538 & 1 & 0.528 & 0.516 & 1 & 0.366 \\
\hline 0.012 & 0.205 & 2.073 & 1 & 1.365 & 2.001 & $/$ & 1.303 & 0.986 & $/$ & 0.886 & 0.535 & 1 & 0.518 & 0.514 & 1 & 0.366 \\
\hline 0.014 & 0.193 & 2.094 & $/$ & 1.365 & 2.026 & $/$ & 1.307 & 1.041 & $/ 1$ & 0.914 & 0.532 & 1 & 0.509 & 0.513 & 1 & 0.366 \\
\hline
\end{tabular}

Table $3 \mathbf{b}$ Partial pressure distribution in the internally insulated wall

\begin{tabular}{|c|c|c|c|c|c|c|c|c|c|c|c|c|c|c|c|c|}
\hline \multirow{2}{*}{$\begin{array}{c}\text { Insulation } \\
\text { thickness, } \\
x_{\text {ins }}(\mathrm{m}) \\
\end{array}$} & \multirow{2}{*}{$\begin{array}{l}\text { Amount of vapour } \\
\text { passing through } \\
\text { wall, } w\left(\mathrm{~g} / \mathrm{m}^{2} \mathrm{~h}\right)\end{array}$} & \multicolumn{15}{|c|}{ saturation pressure $\left(P_{\mathrm{s}}\right)$ / partial pressure $(P)$} \\
\hline & & \multicolumn{3}{|c|}{1} & \multicolumn{3}{|c|}{2} & \multicolumn{3}{|c|}{3} & \multicolumn{3}{|c|}{4} & \multicolumn{3}{|c|}{5} \\
\hline 0 & 0.324 & 1.872 & 1 & 1.364 & 1.772 & 1 & 1.267 & 1.772 & 1 & 1.267 & 0.563 & 1 & 0.606 & 0.530 & 1 & 0.366 \\
\hline 0.002 & 0.295 & 1.918 & 1 & 1.364 & 1.824 & 1 & 1.275 & 1.601 & 1 & 1.187 & 0.556 & 1 & 0.585 & 0.526 & 1 & 0.366 \\
\hline 0.004 & 0.271 & 1.958 & 1 & 1.364 & 1.869 & 1 & 1.283 & 1.469 & 1 & 1.120 & 0.551 & 1 & 0.567 & 0.523 & 1 & 0.366 \\
\hline 0.006 & 0.251 & 1.992 & 1 & 1.364 & 1.908 & 1 & 1.289 & 1.363 & 1 & 1.064 & 0.546 & 1 & 0.552 & 0.520 & 1 & 0.366 \\
\hline 0.008 & 0.233 & 2.022 & 1 & 1.365 & 1.943 & 1 & 1.295 & 1.277 & 1 & 1.015 & 0.542 & 1 & 0.539 & 0.518 & 1 & 0.366 \\
\hline 0.010 & 0.218 & 2.049 & 1 & 1.365 & 1.974 & 1 & 1.299 & 1.206 & 1 & 0.972 & 0.538 & 1 & 0.528 & 0.516 & 1 & 0.366 \\
\hline 0.012 & 0.205 & 2.073 & 1 & 1.365 & 2.001 & 1 & 1.303 & 1.146 & 1 & 0.935 & 0.535 & 1 & 0.518 & 0.514 & 1 & 0.366 \\
\hline 0.014 & 0.193 & 2.094 & 1 & 1.365 & 2.026 & 1 & 1.307 & 1.096 & 1 & 0.902 & 0.532 & 1 & 0.509 & 0.513 & 1 & 0.366 \\
\hline
\end{tabular}

Table 3c Partial pressure distribution in the sandwich insulated wall

\begin{tabular}{|c|c|c|c|c|c|c|c|c|c|c|c|c|c|c|c|c|c|c|c|}
\hline \multirow{2}{*}{$\begin{array}{c}\text { Insulation } \\
\text { thickness, } \\
x_{\text {ins }}(\mathrm{m}) \\
\end{array}$} & \multirow{2}{*}{$\begin{array}{l}\text { Amount of vapour } \\
\text { passing through } \\
\text { wall, } w\left(\mathrm{~g} / \mathrm{m}^{2} \mathrm{~h}\right)\end{array}$} & \multicolumn{18}{|c|}{ saturation pressure $\left(P_{\mathrm{s}}\right) /$ partial pressure $(P)$} \\
\hline & & \multicolumn{3}{|c|}{1} & \multicolumn{3}{|c|}{2} & \multicolumn{3}{|c|}{3} & \multicolumn{3}{|c|}{4} & \multicolumn{3}{|c|}{5} & \multicolumn{3}{|c|}{6} \\
\hline 0 & 0.324 & 1.872 & $/$ & 1.364 & 1.772 & 1 & 1.267 & 1.020 & 1 & 0.937 & 1.020 & 7 & 0.937 & 0.563 & & 0.606 & 0.530 & $/$ & 0.366 \\
\hline 0.002 & 0.295 & 1.918 & $/$ & 1.364 & 1.824 & 1 & 1.275 & 1.103 & 1 & 0.975 & 0.961 & $t$ & 0.886 & 0.556 & & 0.585 & 0.526 & $/$ & 0.366 \\
\hline 0.004 & 0.271 & 1.958 & 1 & 1.364 & 1.869 & 1 & 1.283 & 1.179 & 1 & 1.006 & 0.914 & $y$ & 0.844 & 0.551 & 1 & 0.567 & 0.523 & 1 & 0.366 \\
\hline 0.006 & 0.251 & 1.992 & $/$ & 1.364 & 1.908 & 1 & 1.289 & 1.247 & 1 & 1.033 & 0.875 & 7 & 0.808 & 0.546 & & 0.552 & 0.520 & $/$ & 0.366 \\
\hline 0.008 & 0.233 & 2.022 & 1 & 1.365 & 1.943 & 1 & 1.295 & 1.308 & 1 & 1.057 & 0.842 & 1 & 0.777 & 0.542 & 1 & 0.539 & 0.518 & 1 & 0.366 \\
\hline 0.010 & 0.218 & 2.049 & $/$ & 1.365 & 1.974 & 1 & 1.299 & 1.364 & 1 & 1.077 & 0.815 & 7 & 0.750 & 0.538 & 7 & 0.528 & 0.516 & 1 & 0.366 \\
\hline 0.012 & 0.205 & 2.073 & $/$ & 1.365 & 2.001 & 1 & 1.303 & 1.415 & 1 & 1.095 & 0.791 & 1 & 0.726 & 0.535 & I & 0.518 & 0.514 & $/$ & 0.366 \\
\hline 0.014 & 0.193 & 2.094 & $/$ & 1.365 & 2.026 & 1 & 1.307 & 1.462 & 1 & 1.110 & 0.771 & 1 & 0.706 & 0.532 & & 0.509 & 0.513 & $/$ & 0.366 \\
\hline
\end{tabular}

\subsection{Effect of Indoor Conditions (Temperature and Humidity) on Insulation Thickness}

Variation of the minimum insulation thickness required to prevent condensation (i.e. optimum insulation thickness) as a function of indoor relative humidity is given in Fig. 3 for $\theta_{o}=0.40$ and 0.70 . It can be seen from Fig. 3(a) that insulation is not required since condensation does not occur in the wall for a certain value of the indoor relative humidity (which is up to approximately $\theta_{i}=0.60$ 
for the externally insulated wall, up to approximately $\theta_{i}=$ 0.65 for the sandwich insulated wall and, up to approximately $\theta_{i}=0.70$ for the internally insulated wall) and $x_{i n s}=0$. However, water vapour transfer from indoor to outdoor environment is increased as indoor humidity increases and this situation induces condensation. Insulation thickness should be increased to avoid this and as it is seen from the figure, the minimum insulation thickness values preventing condensation increase with increasing indoor relative humidity for all three applications.

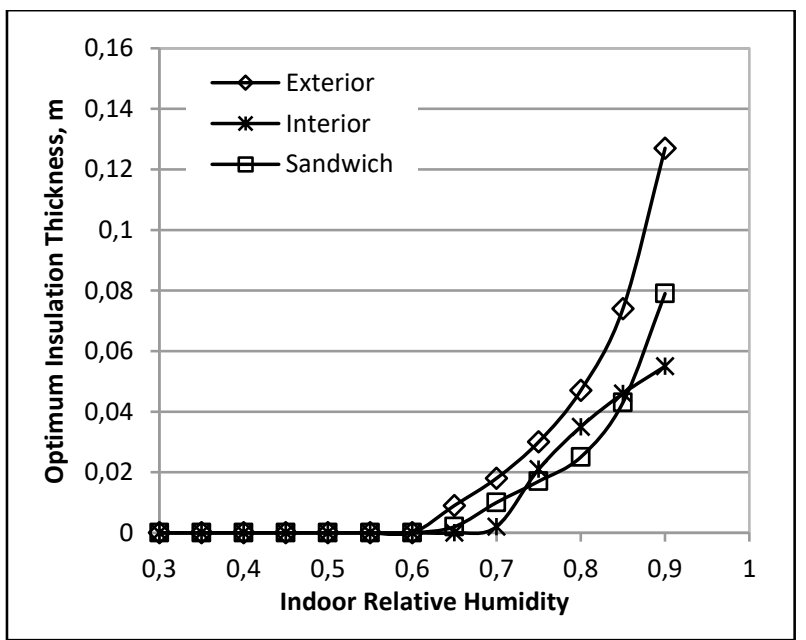

(a)

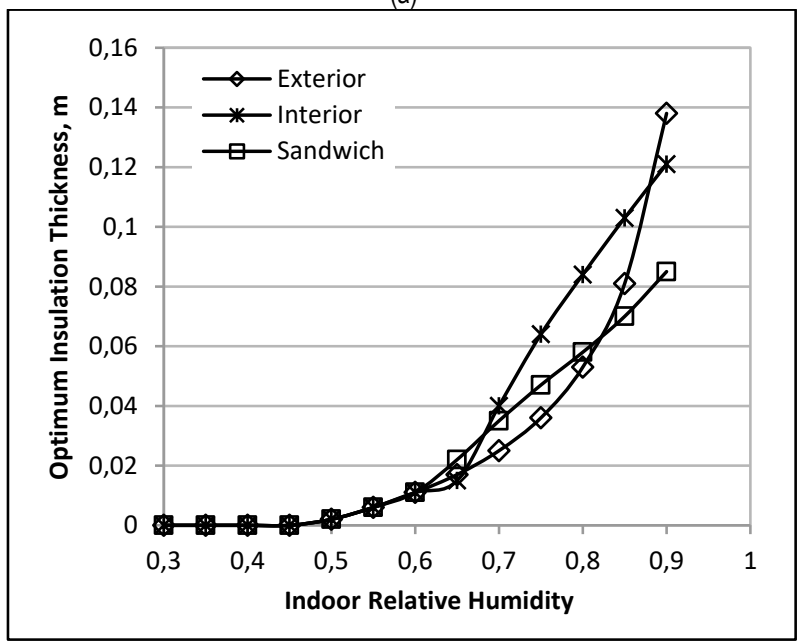

(b)

Figure 3 Variation of optimum insulation thickness as a function of indoor relative humidity for three different applications $\left(T_{i}=22{ }^{\circ} \mathrm{C}, T_{o}=-3{ }^{\circ} \mathrm{C}\right)$ (a) $\theta_{o}=0.40$, (b) $\theta_{o}=0.70$

Condensation occurs on the outer surface of the insulation material for the internal insulation application. Saturation pressure and the partial pressure decreases as the insulation thickness increases. However, since the decrease in the partial pressure is more than that of saturation pressure, it catches up with the partial pressure at a certain value of the insulation thickness and thus condensation is prevented. Condensation is seen on the inner surface of the insulation material for the externally and sandwich insulated walls unlike internally insulated application. In this case, saturation pressure on this surface should reach the partial pressure of water vapour in order to prevent condensation. Increase in saturation pressure is too close to one another for both (external and the sandwich) applications as the insulation thickness increases. However, increase in the partial pressure of water vapour is lower in the sandwich wall due to location of the insulation; therefore, condensation is avoided with the saturation pressure catching up with the partial pressure more quickly. Thus, required insulation thickness for the sandwich application is found as lower than the externally insulated application (Fig. 3(a)).

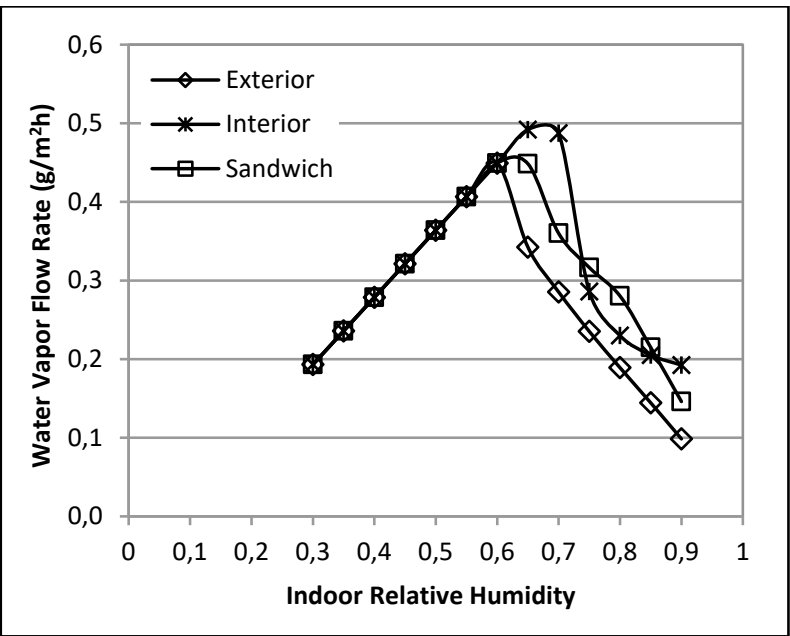

(a)

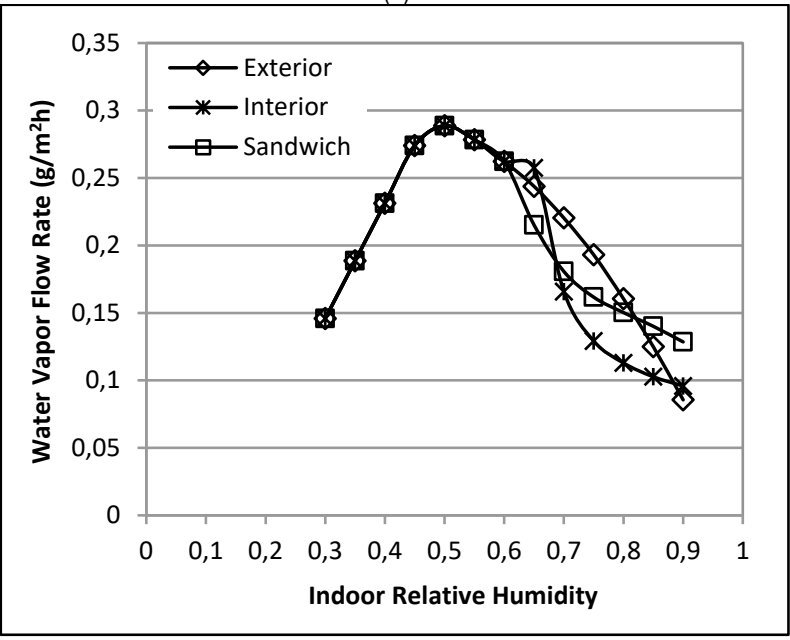

(b)

Figure 4 Water vapour flow rate through the wall at the optimum insulation thickness values for three different applications $\left(T_{i}=22^{\circ} \mathrm{C}, T_{o}=-3{ }^{\circ} \mathrm{C}\right)$ (a) $\theta_{o}=0.40$, (b) $\theta_{o}=0.70$

In conditions with a high value of indoor relative humidity (approx. $\theta_{i}>0.60$ ), the internally insulated application generally requires more stable and smaller insulation thickness relative to other applications. Externally insulation application is considered inappropriate for conditions with a high value of indoor relative humidity. Amount of water vapour passing through wall decreases as outdoor relative humidity increases as a result of the decrease of the partial pressure difference between the indoor and outdoor environments; however, partial pressure of water vapour in the wall increases. This situation increases the risk of condensation (since partial pressures approach the saturation pressure). Therefore, if the outdoor relative humidity increases from 0.40 to 0.70 , the required insulation thickness increases for all three applications (Fig. 3(b)). In general, insulation thicknesses for sandwich application are found to be more 
stable and smaller than the other applications considered in this study.

Variations of water vapour flow rate through the wall as a function of indoor relative humidity for the same indoor and outdoor conditions are given in Fig. 4. In all three insulation applications, pressure difference between indoor and outdoor environments increases with increasing indoor relative humidity and, thus water vapour flow rate increases to a certain value as can be seen in Fig. 4(a) and 4(b). However, after this value, water vapour transfer from indoor to outdoor environment decreases abruptly due to insulation. Since the insulation thickness required to prevent condensation for the externally insulated wall is greater than the other applications at $\theta_{o}=0.40$ (see Fig. 3(a)), a lower water vapor flow rate is observed in this application (Fig. 4(a)).

When the outdoor relative humidity is increased (from 0.40 to 0.70 ), partial pressure of water vapour difference between indoor and outdoor environments decreases and therefore, water vapour flow rate is generally lower (Fig. 4(b)).

For all three different applications, variation of the minimum insulation thickness required to prevent condensation as a function of indoor temperature is given in Fig. 5. As shown in Fig. 5(a), since there is no condensation on the wall until indoor temperature reaches a certain value (approximately $21^{\circ} \mathrm{C}$ ), insulation is not required $x_{i n s}=0$. However, partial pressure of water vapour difference between the indoor and the outdoor environments grows as indoor temperature increases (provided indoor and outdoor relative humidity values remain constant) and this situation increases the risk of condensation. Therefore, the insulation thickness required to prevent condensation with increasing temperature increases for all three applications. The minimum insulation thickness necessary for all three applications is the same until the indoor temperature reaches a certain condition (about $29^{\circ} \mathrm{C}$ ). However, an increasing risk of condensation is observed on the inner layers of the wall in the sandwich insulated wall application as indoor temperature further increases and the optimum insulation thickness is found to be greater than the other applications considered in this study.

As it is shown in Fig. 5(b), amount of water vapour passing from indoor to outdoor environment is greater at the high indoor relative humidity condition $\left(\theta_{i}=0.80\right)$ for all three applications and therefore condensation takes place within inner layers of the wall. The optimum insulation thicknesses increase to avoid the risk of condensation for all three applications (Fig. 5(b)).

Condensation begins on the outer surface of the insulation material at high indoor humidity for the internally insulated and the sandwich insulated applications. Saturation and partial pressure of water vapour decrease as the insulation thickness increases on this surface. In order to prevent condensation, the decrease in partial pressure of water vapour should be greater and it should reach the saturation pressure at a certain insulation thickness. However, unlike this situation, partial and saturation pressures increase as indoor temperature increases. Difference between partial pressure of water vapour and the saturation pressure is greater due to the location of the insulation material and difference in surface temperatures, for internal insulation application. Therefore, partial pressure of water vapor could reach the saturation pressure at higher values of insulation thickness compared to other applications for internally insulated walls with increasing temperature (Fig. 5(b)). For the externally insulated wall, at high indoor relative humidity conditions, condensation is observed on the inner surface of the insulating material. Saturation and partial pressure of water vapour are increased as the insulation thickness increases on this surface. The increase in saturation pressure should be greater in order to prevent condensation and it should reach the partial pressure of water vapour. Since the saturation and partial pressure of water vapour increase with increasing indoor temperature, condensation could be prevented at smaller insulation thicknesses compared to other applications (Fig. 5(b)).

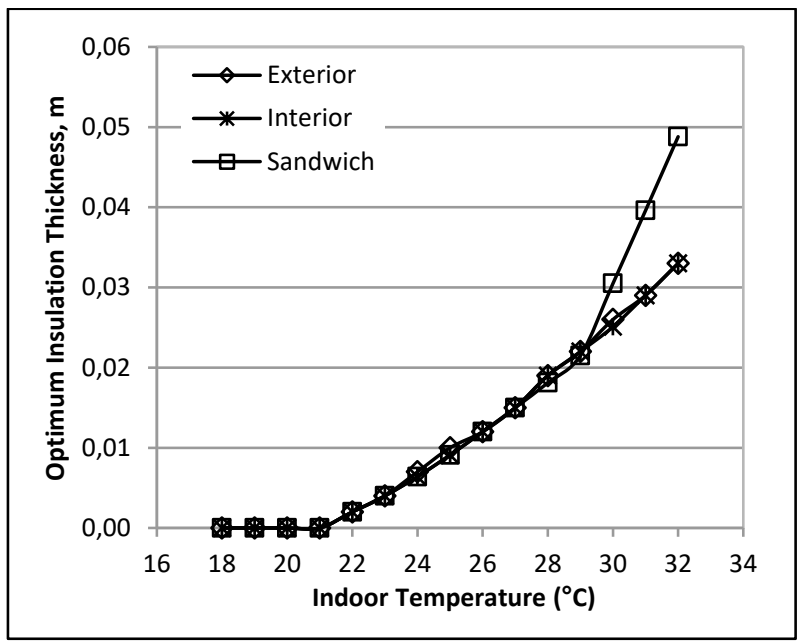

(a)

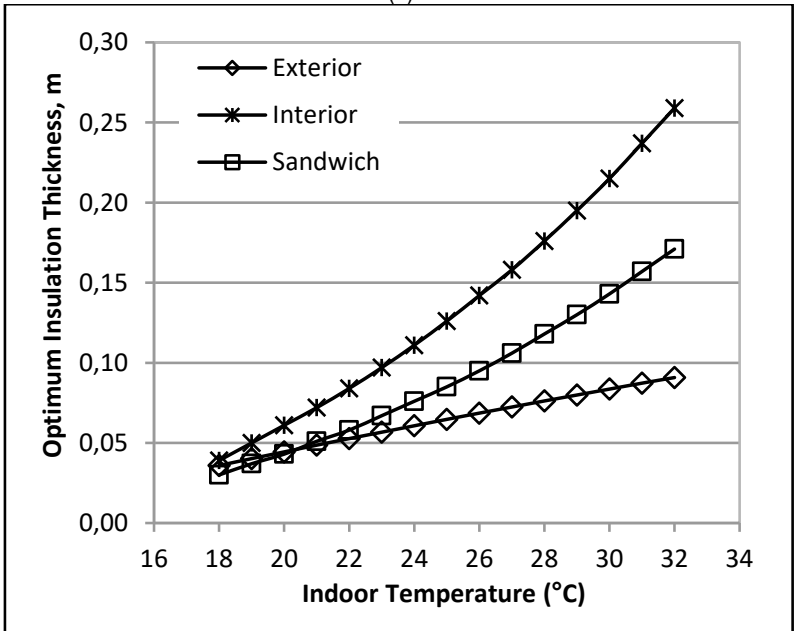

(b)

Figure 5 Variation of optimum insulation thickness as a function of indoor temperature for three different applications $\left(T_{o}=-3{ }^{\circ} \mathrm{C}, \theta_{o}=0.70\right)$ (a) $\theta_{i}=0.50$, (b) $\theta_{i}=0.80$

If the indoor relative humidity is at low and medium levels $\left(\theta_{\mathrm{i}}<0.60\right)$, there is no significant effect of the insulation application model on the optimum insulation thickness. However, at high indoor relative humidity conditions, the minimum insulation thickness values required to prevent condensation are obtained for the external insulation applications. Therefore, the external insulation application can be considered more suitable for 
locations having different indoor temperatures in terms of condensation risk. If an internal insulation is applied, the required insulation thickness will be greater than the other two applications.

Variation of water vapour flow rate through the wall is given in Fig. 6 as a function of indoor temperature at the aforementioned conditions for all three applications. For $\theta_{i}=0.50$, as it is also shown in Fig. 6(a), amount of water vapour transferred through the wall increases up to indoor temperature value since there is no need for insulation till a certain value of temperature (about 21 $\left.{ }^{\circ} \mathrm{C}\right)$. Then, an increasing resistance is observed due to application of insulation to prevent condensation and amount of water vapour transferred from indoor to outdoor environment decreases for all three applications. Water vapour flow rates are the same for all applications since the minimum insulation thicknesses for all applications are the same until the indoor temperature reaches about $29{ }^{\circ} \mathrm{C}$. However, at higher temperatures (starting at $29{ }^{\circ} \mathrm{C}$ ), water vapour flow rates are lower for the sandwich insulated applications due to larger insulation thickness (Fig. 6(a)).

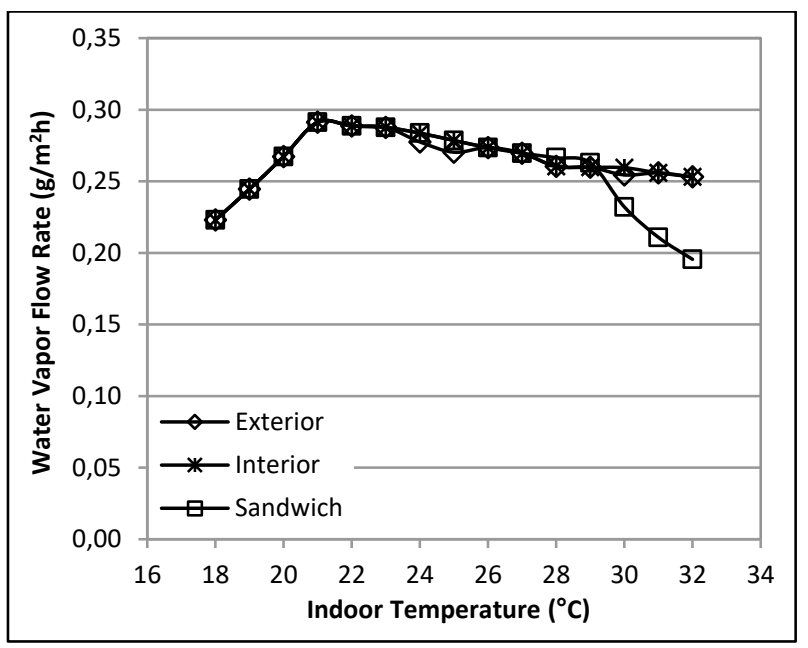

(a)

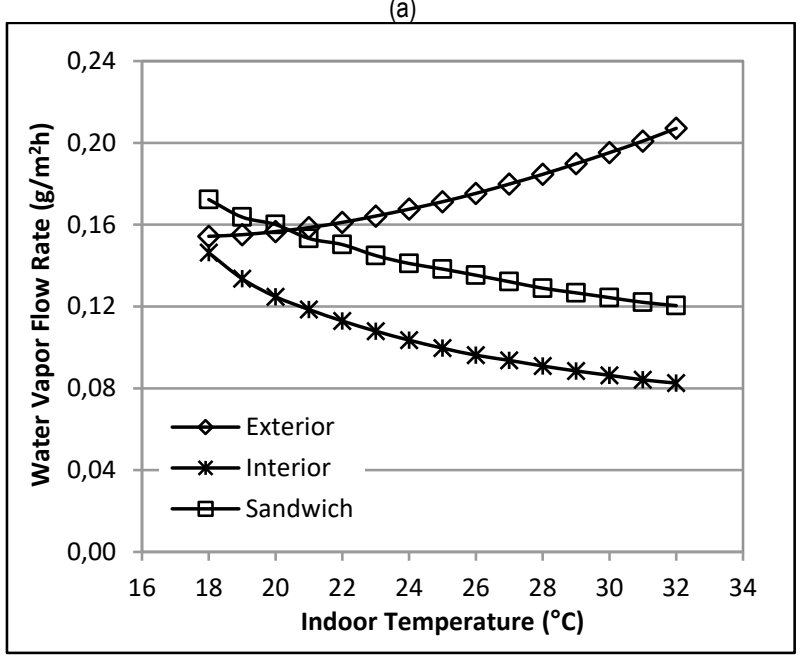

(b)

Figure 6 Water vapour flow rate through the wall at the optimum insulation thickness values for three different applications $\left(T_{o}=-3{ }^{\circ} \mathrm{C}, \theta_{o}=0.70\right)$

(a) $\theta_{i}=0.50$, (b) $\theta_{i}=0.80$

When the indoor relative humidity is increased from 0.50 to 0.80 , the required partial pressure difference of water vapor between indoor and outdoor environments and accordingly the minimum insulation thickness inceases. Therefore, amount of water vapor transferred is calculated to be smaller in all three insulation applications for $\theta_{i}=0.80$ by the effect of increased insulation thickness.

For the internal and sandwich insulation applications, the insulation thickness required to prevent condensation is greater than the external insulation applications (Fig. 5(b)). Therefore, amount of water vapour transferred continues to increase in external insulation application (due to a smaller value of required insulation thickness) while amount of water vapour transferred through the wall decreases in both applications (which are internal and sandwich insulations) due to a greater value of insulation thickness (Fig. 6(b))

\subsection{Effect of Outdoor Conditions (Temperature and Humidity) on Insulation Thickness}

Effect of outdoor relative humidity on the optimum insulation thickness is given for $\theta_{i}=0.50$ and 0.80 in Fig. 7 for all three applications. It is observed that there is no need for insulation and $x_{i n s}=0$ since no condensation occurs on the wall for certain outdoor relative humidity conditions (up to $\theta_{o}=0.65$ in all three applications). Partial pressure of outdoor water vapor increases in accordance with the outdoor relative humidity and the water vapor transfer decreases. However, partial pressure of water vapor inside the wall increases parallel to outdoor relative humidity and approaches to the saturation pressure. This increases the risk of condensation in the wall layers. Therefore, the required insulation thickness depending on the increasing outdoor relative humidity increases for all three applications. In particular, the rate of increase of the optimum insulation thickness is higher at high values of outdoor relative humidity. When the insulation applications are examined for $\theta_{i}=0.50$, it is observed that the condensation existing on the wall occurs on the outer layer (at the inner surface of the external plastering) for all three applications. The required insulation thickness is the same for all three applications since the pressure and temperature conditions in this layer are the same (Fig. 7(a)).

In all three applications, amount of water vapour transferred from indoor to outdoor environment, and accordingly, the required insulation thickness increases with increasing indoor relative humidity (from $\theta_{i}=0.50$ to 0.80$)$. At high indoor relative humidity conditions, condensation takes place on the outer surface of insulation for the internal and sandwich insulation applications. In order to prevent condensation, decrease in partial pressure of water vapour should be greater and it should reach the saturation pressure at a certain insulation thickness. However, partial pressure of water vapour increases in parallel to the outdoor relative humidity and thus the difference between the partial pressure of water vapour and the saturation pressure increases due to the location of the insulation material for internal insulation application. Therefore, for internal insulation applications, partial pressure of water vapour could reach the saturation pressure at higher insulation thicknesses (Fig. 7(b)).

It is observed that application location of the insulation has no significant effect on the optimum 
thickness at low and medium indoor relative humidity levels (Fig. 7(a)). However, it can be considered that the external insulation application is more appropriate for a wide range of outdoor relative humidity values at high indoor relative humidity levels. In case of both indoor and outdoor relative humidity values are high, an increased risk of condensation is observed in the wall layers and, therefore, the optimum insulation thicknesses reach extremely high values. In addition, when Fig. 7(a) and Fig. 7(b) are analyzed together, it is observed that the effect of outdoor relative humidity has a significant effect on the optimum insulation thickness especially at higher indoor relative humidity conditions.

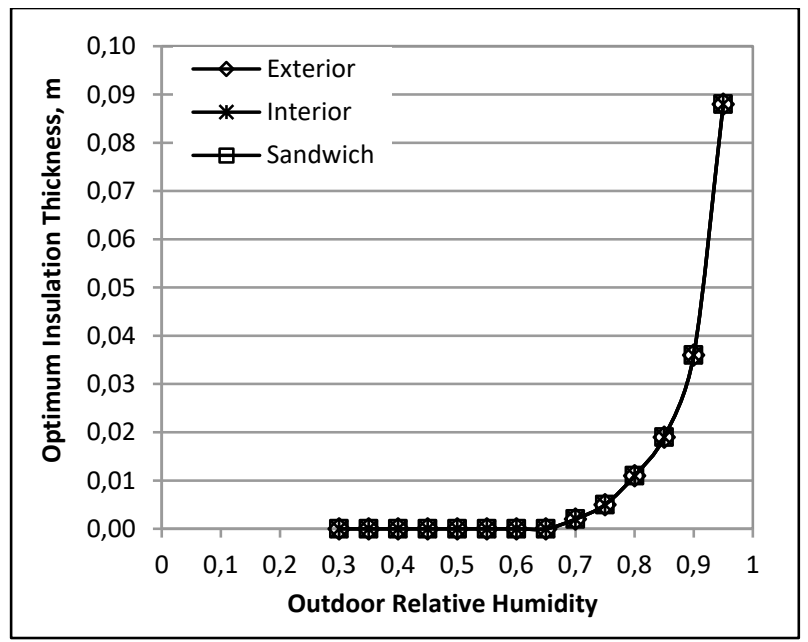

(a)

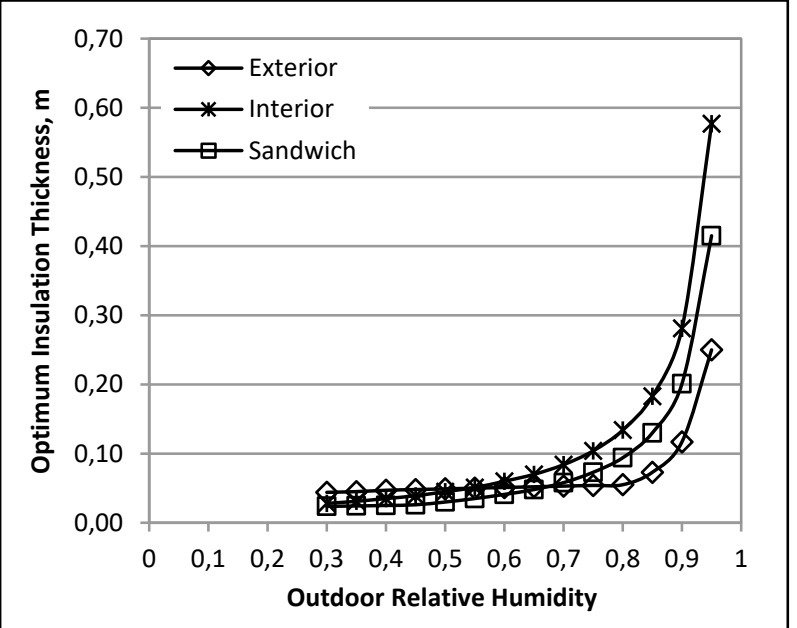

(b)

Figure 7 Variation of optimum insulation thickness as a function of outdoor relative humidity for three different applications $\left(T_{o}=-3{ }^{\circ} \mathrm{C}, T_{i}=22{ }^{\circ} \mathrm{C}\right)$ (a) $\theta_{i}=0.50$, (b) $\theta_{i}=0.80$

Variation of water vapour flow rate as a function of outdoor relative humidity is given in Fig. 8. Since the optimum insulation thickness increases with increasing outdoor relative humidity, amount of water vapour transferred from indoor to outdoor environment decreases (Fig. 8(a) and (b)). It is observed that amount of water vapor transferred from the wall is the same for three different insulation applications regarding the optimum insulation thicknesses are also the same (Fig. 7(a)). For $\theta_{i}$ $=0.50$, in all three insulation applications, water vapor flow rate transferred from indoor to outdoor environment decreases due to decreasing indoor and outdoor partial pressure difference of water vapour up to the insulation material surface (up to $\theta_{o}=0.65$ ), then, decrease becomes faster as a result of insulation added to this effect (Fig. $8(\mathrm{a})$ ).

As the optimum insulation thickness increases with increasing indoor relative humidity (from 0.50 to 0.80 ), the water vapor flow rate decreases for all three applications (Fig. 8(a) and (b)). Since the minimum insulation thickness required for the internally insulated wall application is greater than the other applications, the water vapour flow rate is calculated to be less. In the externally insulated wall application, a more rapid drop is observed in the amount of water vapour transferred since a more significant increase occurs in the thickness of the required insulation after $\theta_{o}=0.80$ (Fig. 8(b)).

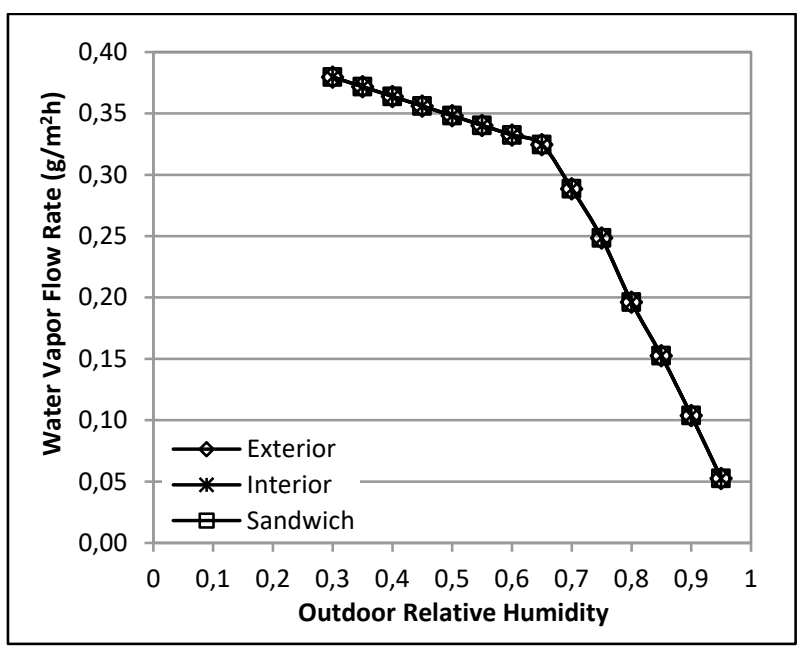

(a)

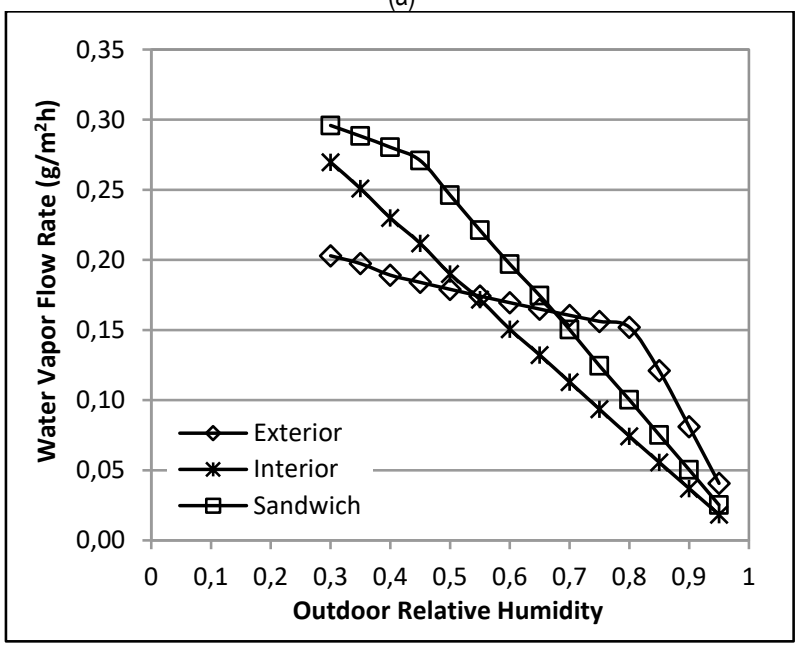

(b)

Figure 8 Water vapour flow rate through the wall at optimum insulation thickness values for three different applications $\left(T_{o}=-3{ }^{\circ} \mathrm{C}, T_{i}=22{ }^{\circ} \mathrm{C}\right)$ (a) $\theta_{i}=0.50$, (b) $\theta_{i}=0.80$

Variation of the insulation thickness that is required to prevent condensation as a function of outdoor temperature is given in Fig. 9. It is observed that there is no need for insulation and $x_{i n s}=0$ since no condensation occurs on the wall when the outdoor temperature is above $-6{ }^{\circ} \mathrm{C}$ for $\theta_{o}=0.40$ and $0{ }^{\circ} \mathrm{C}$ for $\theta_{o}=0.80$. However, partial pressure difference of the water vapour between the indoor and outdoor environments increases at lower temperatures therefore the required minimum insulation thickness increases. 
For the internal and sandwich insulation applications, condensation takes place at inner layers (on the outer surface of insulation) at low outdoor temperatures $(-12$ ${ }^{\circ} \mathrm{C}$ and below). However, for the external insulation application, condensation is observed on the outer layers at low outdoor temperatures due to the location of the insulation material. Condensation can be prevented with smaller insulation thickness values for the external insulation application because a smaller insulation thickness is required to prevent condensation occurring on the outer layer (Fig. 9(a)).

As is apparent in Fig. 9(a) and (b), outdoor partial pressure of water vapour increases with increasing outdoor relative humidity (from 0.40 to 0.80 ) and amount of water vapour transferred from the wall decreases. However, with increasing outdoor relative humidity, partial pressure of water vapour values within the wall increase and get closer to the saturation pressures. This increases the risk of condensation in the wall layers. Therefore, because of increasing outdoor relative humidity, the required insulation thickness increases for all three applications (Fig. 9(b)).
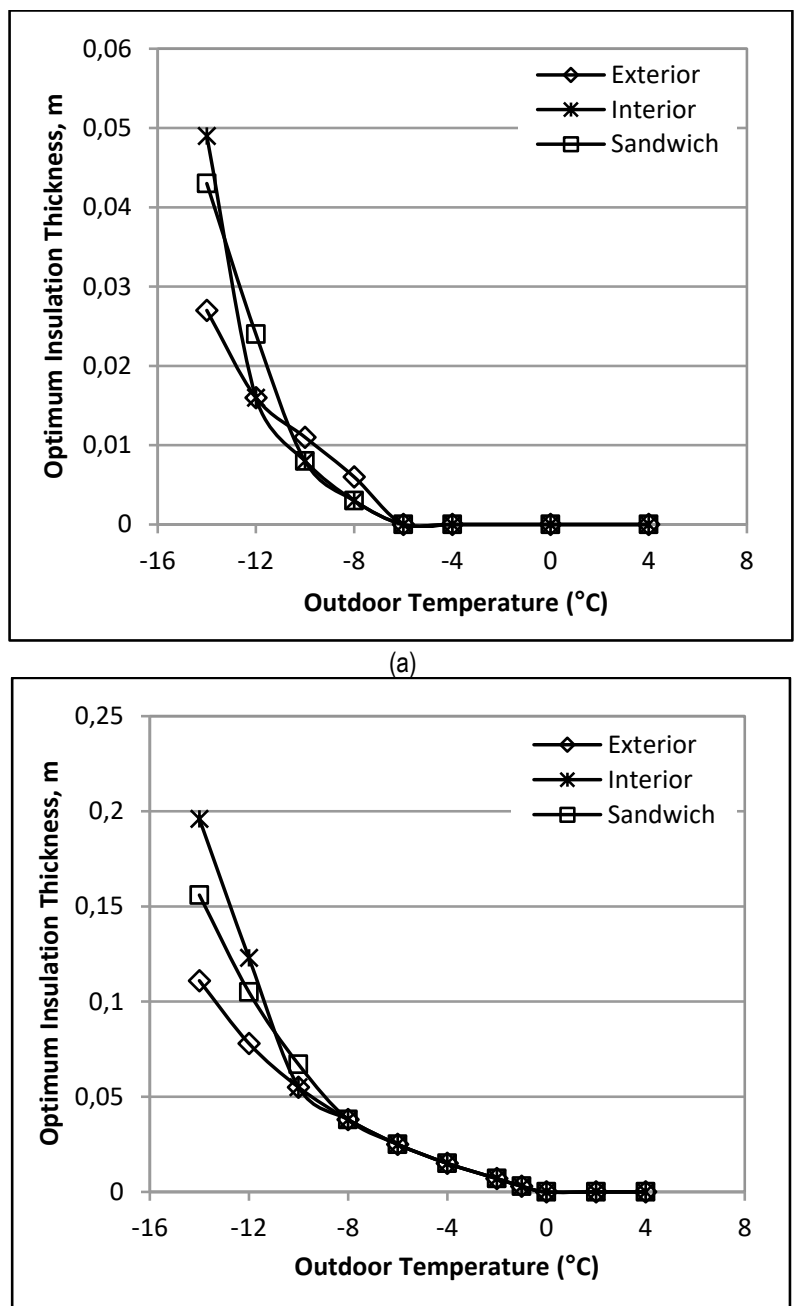

(b)

Figure 9 Variation of the optimal insulation thickness as a function of the outdoor temperature for three different applications $\left(T_{i}=22^{\circ} \mathrm{C}, \theta_{i}=0.50\right)$ (a) $\theta_{o}=0.40$, (b) $\theta_{o}=0.80$

For externally insulated wall applications at high outdoor relative humidity conditions, condensation takes place on the outer layers of the wall at low outdoor temperatures and the required insulation thickness is found to be lower for the externally insulated wall applications in comparison to the other applications. However, condensation is observed on the outer layer (at the inner surface of the external plastering) of the wall for all three applications as the outdoor temperature increases (from $-8{ }^{\circ} \mathrm{C}$ ) and, therefore, the required insulation thickness is found to be the same (Fig. 9(b)).

Variation of water vapour flow rate through the wall is given as a function of outdoor temperature at the aforementioned conditions for all three applications (Fig. 10). It was expected that the amount of water vapour transferred through the wall would decrease with increasing outdoor temperature; however it increased due to a decrease in the thickness of the existing insulation. Amount of water vapour transferred through the wall decreases with increasing outdoor temperature since there is no need for insulation at temperatures higher than -6 ${ }^{\circ} \mathrm{C}$ for $\theta_{o}=0.40$ and $0^{\circ} \mathrm{C}$ for $\theta_{o}=0.80$. Partial pressure of water vapour difference between the indoor and outdoor environments decreases with increasing outdoor relative humidity (from 0.40 to 0.80 ) therefore, water vapour flow rate is generally lower (Fig. 10(b)).

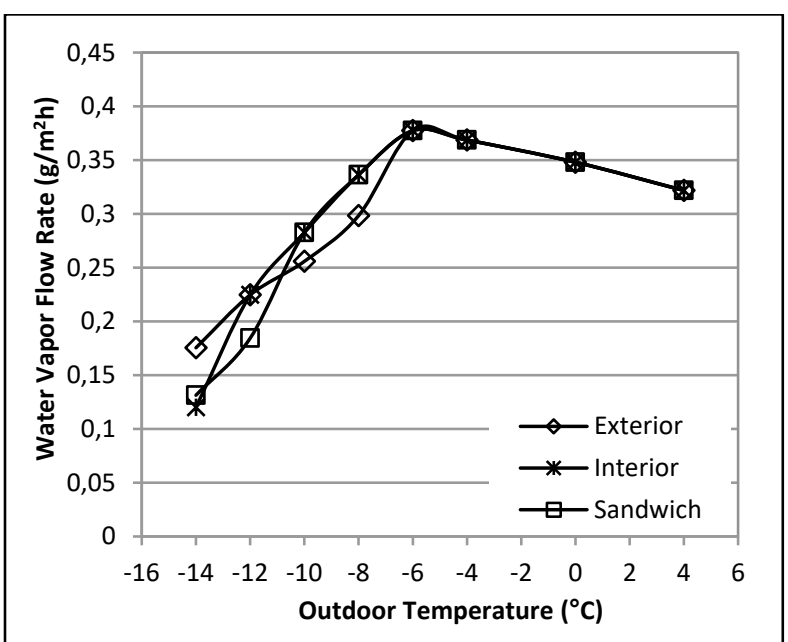

(a)

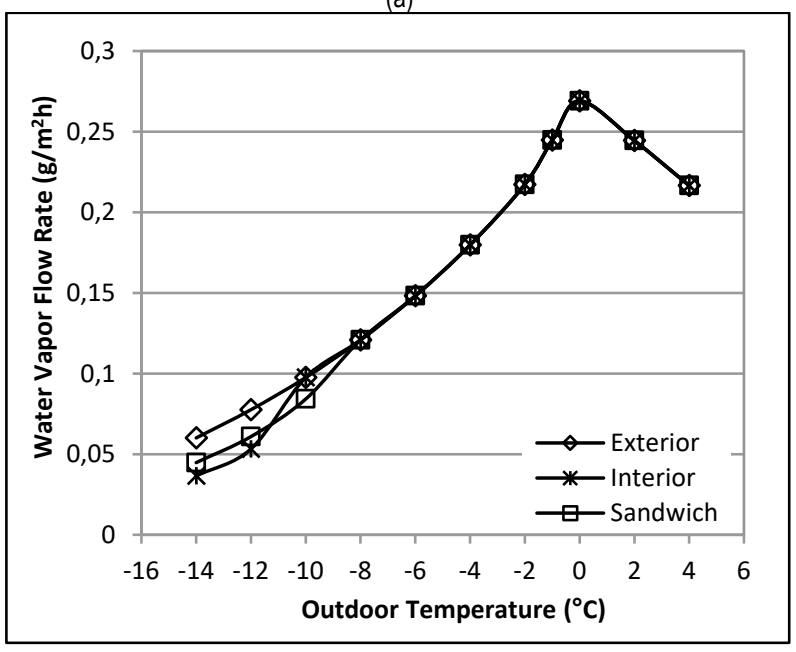

(b)

Figure 10 Water vapour flow rate through the wall at the optimum insulation thickness values for three different applications $\left(T_{i}=22^{\circ} \mathrm{C}, \theta_{i}=0.50\right)$ (a) $\theta_{o}=0.40$, (b) $\theta_{o}=0.80$ 


\section{CONCLUSION}

In this study, effect of indoor-outdoor conditions on condensation event was investigated for various insulation applications (internal, external and sandwich insulation) having the same thermal resistance and the required insulation thickness values were calculated. The results obtained are:

- The risk of condensation significantly increases with increasing relative humidity difference between the indoor and outdoor environments. In a similar manner, the risk of condensation increases with increasing indoor and outdoor temperature difference resulting in a heat and water vapour flow from indoor to outdoor environment. It is therefore necessary to increase the insulation thickness in order to prevent condensation in the wall material in case of a high temperature and relative humidity difference between the indoor and outdoor environments.

- $\quad$ Outdoor relative humidity has a significant effect on the optimum insulation thickness especially at high indoor relative humidity.

- Both environments (indoor and outdoor) have a high value of relative humidity which increases the risk of condensation.

- Type of insulation applications does not have a significant effect on the optimum insulation thickness when the indoor relative humidity is at low and medium levels.

- External insulation is more suitable with respect to the conditions where the indoor relative humidity is at high level. At different indoor temperatures, smaller optimum insulation thicknesses were obtained for this application.

- In cases where the outdoor relative humidity is high, smaller insulation thicknesses are obtained for the external insulation application in comparison to the other types of applications. Furthermore, it is observed that effect of type of insulation applications on the optimum insulation thickness is more pronounced at low outdoor temperatures. It can be concluded that the external insulation application gives better results also at these conditions.

\section{REFERENCES}

[1] Kaynakli, O. (2008). Study on residential heating energy requirement and optimum insulation thickness. Renewable Energy, 33(6), 1164-1172. https://doi.org/10.1016/j.renene.2007.07.001

[2] Kurekci, A., Bardakci, A. T., Cubuk, H., \& Emanet, O. (2012). Determination of the optimum insulation thickness for all cities of Turkey. HVAC and Sanitary Engineering, 131, 5-21.

[3] Gurel, A. E. \& Cingiz, Z. (2011). Economical analysis of determination thermal insulation thickness for different external walls. Sakarya University Journal of Science, 15(1), 75-81.

[4] Zhu, P., Huckemann, V., \& Fisch, M. N. (2011). The optimum thickness and energy saving potential of external wall insulation in different climate zones of China. Procedia Engineering, 21, 608-616. https://doi.org/10.1016/j.proeng.2011.11.2056

[5] Aksoy, U. T. \& Aytac, A. (2006).The relation between optimum insulation thickness and heating cost on external walls for energy saving. Journal of the Faculty of Engineering and Architecture of Gazi University, 21(4), 753-758.

[6] Comakli, K. \& Yuksel, B. (2003). Optimum insulation thickness of external walls energy saving. Applied Thermal Engineering, 23, 473-479. https://doi.org/10.1016/S1359-4311(02)00209-0

[7] Sisman, N., Kahya, E., Aras, N., \& Aras, H. (2007). Determination of optimum insulation thicknesses of the external walls and roof (ceiling) for Turkey's different degree-day regions. Energy Policy, 35, 5151-5155. https://doi.org/10.1016/j.enpol.2007.04.037

[8] Bolatturk, A. (2006). Determination of optimum insulation thickness for building walls with respect to various fuels and climate zones in Turkey. Applied Thermal Engineering, 26, 1301-1309. https://doi.org/10.1016/j.applthermaleng.2005.10.019

[9] Yu, J., Yang, C., Tian, L., \& Liao, D. (2009). A study on optimum insulation thicknesses of external walls in hot summer and cold winter zone of China. Applied Energy, 86, 2520-2529. https://doi.org/10.1016/j.apenergy.2009.03.010

[10] Bolatturk, A. (2008). Optimum insulation thicknesses for building walls with respect to cooling and heating degreehours in the warmest zone of Turkey. Building and Environment, 43(6), 1055-1064. https://doi.org/10.1016/j.buildenv.2007.02.014

[11] Ozel, M. \& Pihtili, K. (2007). Investigation of the most suitable location of insulation applying on building roof from maximum load levelling point of view. Building and Environment, 42, 2360-2368. https://doi.org/10.1016/j.buildenv.2006.05.006

[12] Kontoleon, K. J. \& Bikas, D. K. (2006). The influence of the zone's indoor temperature settings on the cooling/heating loads for fixed and controlled ventilation. Building and Environment, 41(2), 75-86. https://doi.org/10.1016/j.buildenv.2005.01.022

[13] Al-Khawaja, M. J. (2004). Determination and selecting the optimum thickness of insulation for buildings in hot countries by accounting for solar radiation. Applied Thermal Engineering, 24, 2601-2610. https://doi.org/10.1016/j.applthermaleng.2004.03.019

[14] Al-Sanea, S. A., Zedan, M. F., Al-Ajlan, S. A., \& Abdul Hadi, A. S. (2003). Heat transfer characteristics and optimum insulation thickness for cavity walls. Journal of Thermal Envelope and Building Science, 26(3), 285-307. https://doi.org/10.1177/109719603027973

[15] Atmaca, S. U. Kargici, S. (2006). Konya'da kış aylarında yap1 malzemelerinde oluşan buhar geçișinin örnekle incelenmesi (in Turkish). Mühendis ve Makine, 47(553), $55-62$.

[16] Heperkan, A. H., Bircan, M. M., Sevindir, M. K. (2001). Yapi malzemelerinde buhar difuzyonu ve yogusma (in Turkish). V. National HVAC and Sanitary Engineering Conference, 03-06 October 2001, Efes Convention Centre, Izmir, Turkey, 461-470.

[17] Arslan, O. \& Kose, R. (2006). Thermoeconomic optimization of insulation thickness considering condensed vapor in buildings. Energy and Buildings, 38, 1400-1408. https://doi.org/10.1016/j.enbuild.2006.02.012

[18] Ucar, A. (2010). Thermoeconomic analysis method for optimization of insulation thickness for the four different climatic regions of Turkey. Energy, 35(4), 1854-1864. https://doi.org/10.1016/j.energy.2009.12.022

[19] Yetim, İ. Y. (2007). Yap1 elemanlarinin ozgul isilarinin ve su buhari difuzyon direnc katsayilarinin belirlenmesi (in Turkish). Dokuz Eylul Universitesi Bitirme Projesi.

[20] Dagsoz, A. K. (1995). Turkiye'de derece-gun sayilari, ulusal enerji tasarruf politikasi, yapilarda isi yalitimi (in Turkish). Istanbul: Izocam. 
[21] Cengel, Y. \& Ghajar, A. (2010). Heat and Mass Transfer: Fundamentals and Applications. $4^{\text {th }}$ ed. McGraw Hill Inc.

[22] Al-Sanea, S. A., Zedan, M. F., \& Al-Ajlan, S. A. (2005). Effect of electricity tariff on the optimum insulation thickness in building walls as determined by a dynamic heat-transfer model. Applied Energy, 82, 313-330. https://doi.org/10.1016/j.apenergy.2004.10.014

\section{Symbols}

$D$ water vapour diffusion coefficient, $\left(\mathrm{m}^{2} / \mathrm{h}\right)$

$h$ convective heat transfer coefficient, $\left(\mathrm{W} / \mathrm{m}^{2}{ }^{\circ} \mathrm{C}\right)$

$k$ thermal conductivity, $\left(\mathrm{W} / \mathrm{m}^{\circ} \mathrm{C}\right)$

$P$ partial pressure of water vapour, $(\mathrm{kPa})$

$q$ heat flux, $\left(\mathrm{W} / \mathrm{m}^{2}\right)$

$R$ gas constant for water vapour, $(\mathrm{N} \mathrm{m} / \mathrm{mg} \mathrm{K})$

$R_{\mathrm{w}}$ thermal resistance of uninsulated wall, $\left(\mathrm{m}^{2}{ }^{\circ} \mathrm{C} / \mathrm{W}\right)$

$T$ temperature $\left({ }^{\circ} \mathrm{C}\right)$

$U$ overall heat transfer coefficient, $\left(\mathrm{W} / \mathrm{m}^{2}{ }^{\circ} \mathrm{C}\right)$

$w$ water vapour flow rate, $\left(\mathrm{kg} / \mathrm{h} \mathrm{m}^{2}\right)$

$x$ thickness of the construction material (m)

$\beta$ vapour permeability coefficient, $\left(\mathrm{kg} / \mathrm{m}^{2} \mathrm{~h} \mathrm{kPa}\right)$

$\delta$ vapour permeability resistance of building material, $(\mathrm{kPa} \mathrm{m} \mathrm{h} / \mathrm{kg})$

$\delta_{\text {air }}$ vapor permeability resistance of air, $(\mathrm{kPa} \mathrm{m} \mathrm{h} / \mathrm{kg})$

$\theta$ relative humidity, (-)

$\mu$ vapor diffusion resistance factor of material, (-)

$\mu_{\mathrm{p}}$ vapour permeability of building material, $(\mathrm{kg} / \mathrm{h} \mathrm{m}$ $\mathrm{kPa})$

\section{Subscript}

i indoor

ins insulation

$n$ number of wall layers

o outdoor

s saturation

\section{Contact information:}

Omer KAYNAKLI, Prof. Dr.

Uludag University, Department of Mechanical Engineering

Gorukle/Bursa, Turkey

E-mail: kaynakli@uludag.edu.tr

Ali Husnu BADEMLIOGLU, postgraduate

Bursa Technical University, Department of Energy Systems Engineering

Yıldırım/Bursa, Turkey

E-mail: husnu.bademlioglu@btu.edu.tr

Hande Tufekci UFAT, Dr.

Uludag University, Department of Mechanical Engineering

Gorukle/Bursa, Turkey

E-mail: handet@uludag.edu.tr 